Article

\title{
Analysis of DC Characteristics in GaN-Based Metal-Insulator-Semiconductor High Electron Mobility Transistor with Variation of Gate Dielectric Layer Composition by Considering Self-Heating Effect
}

\author{
In-Tae Hwang ${ }^{1}$, Kyu-Won Jang ${ }^{1}$, Hyun-Jung Kim ${ }^{1}$, Sang-Heung Lee ${ }^{2}$, Jong-Won Lim ${ }^{2}$, \\ Jin-Mo Yang ${ }^{3}$, Ho-Sang Kwon ${ }^{3}$ and Hyun-Seok Kim ${ }^{1, *(1)}$ \\ 1 Division of Electronics and Electrical Engineering, Dongguk University-Seoul, Seoul 04620, Korea \\ Electronics and Telecommunications Research Institute, Daejeon 34129, Korea \\ 3 Agency for Defense Development, Daejeon 34186, Korea \\ * Correspondence: hyunseokk@dongguk.edu; Tel.: +82-2-2260-3996
}

Received: 17 July 2019; Accepted: 30 August 2019; Published: 2 September 2019

check for updates

\begin{abstract}
This study investigates metal-insulator-semiconductor high electron mobility transistor DC characteristics with different gate dielectric layer compositions and thicknesses, and lattice temperature effects on gate leakage current by using a two-dimensional simulation. We first compared electrical properties, including threshold voltage, transconductance, and gate leakage current with the self-heating effect, by applying a single $\mathrm{Si}_{3} \mathrm{~N}_{4}$ dielectric layer. We then employed different $\mathrm{Al}_{2} \mathrm{O}_{3}$ dielectric layer thicknesses on top of the $\mathrm{Si}_{3} \mathrm{~N}_{4}$, and also investigated lattice temperature across a two-dimensional electron gas channel layer with various dielectric layer compositions to verify the thermal effect on gate leakage current. Gate leakage current was significantly reduced as the dielectric layer was added, and further decreased for a 15-nm thick $\mathrm{Al}_{2} \mathrm{O}_{3}$ on a 5-nm $\mathrm{Si}_{3} \mathrm{~N}_{4}$ structure. Although the gate leakage current increased as $\mathrm{Al}_{2} \mathrm{O}_{3}$ thickness increased to $35 \mathrm{~nm}$, the breakdown voltage was improved.
\end{abstract}

Keywords: GaN; metal-insulator-semiconductor high electron mobility transistor; gate leakage current; two-dimensional electron gas; breakdown voltage

\section{Introduction}

GaN-based high electron mobility transistors (HEMTs) have been studied as promising power devices for various applications, such as a communication base transceiver station and military radar equipment, due to their superior material characteristics, including high breakdown voltage, high electron mobility, high thermal conductivity, and wide bandgap [1-3]. However, a gate leakage current degrades a device's electrical properties, power efficiency, and stability during operation. Generally, a gate leakage current is affected by a high lattice temperature and electric field and occurs mostly near the drain-side gate head edge [4-10]. When an insulator is placed between the gate metal and semiconductor, i.e., metal-insulator-semiconductor field-effect transistor, an electric field generated by the gate voltage is strongly formed in the insulator having a large resistance, such that the input impedance becomes very large and the gate leakage current can be reduced. Gate leakage current in GaN-based HEMTs can be reduced using structures similar to metal-insulator-semiconductor high electron mobility transistors (MIS-HEMTs), where high-k materials, such as $\mathrm{Si}_{3} \mathrm{~N}_{4}$ and $\mathrm{Al}_{2} \mathrm{O}_{3}$, are deposited under the gate metal [11-18]. MIS-HEMTs have been studied by adding a high quality single 
dielectric layer, such as $\mathrm{Si}_{3} \mathrm{~N}_{4}, \mathrm{Al}_{2} \mathrm{O}_{3}, \mathrm{SiO}_{2}, \mathrm{HfO}_{2}, \mathrm{Sc}_{2} \mathrm{O}_{3}, \mathrm{GaO}_{3}$, or $\mathrm{ZrO}_{2}$, to suppress current collapse, improve current flow, and reduce gate leakage current $[14-17,19,20]$. However, various dielectric layers deposited on top of a GaN-based HEMT cause an interface state trap and mechanical stresses, resulting in changes in threshold voltage and carrier concentration, respectively. Therefore, appropriate dielectric material and thickness selections are required. The $\mathrm{Si}_{3} \mathrm{~N}_{4}$ dielectric layer causes compressive stress, but the $\mathrm{Al}_{2} \mathrm{O}_{3}$ dielectric layer deposited on the $\mathrm{Si}_{3} \mathrm{~N}_{4}$ dielectric layer generates tensile stress. Since proper tensile stress helps to increase the carrier concentration compared to compressive stress, the combination of $\mathrm{Si}_{3} \mathrm{~N}_{4}$ and $\mathrm{Al}_{2} \mathrm{O}_{3}$ layer thicknesses is very important [21].

This study investigated transfer I-V characteristics, gate leakage current, lattice temperature across two-dimensional electron gas (2-DEG) channel layer, and MIS-HEMT drain current variation by changing the dielectric layer compositions and thicknesses with the help of a two-dimensional simulator [22]. To begin with, we compared electrical properties, including threshold voltage, transconductance, and gate leakage current with the self-heating effect (SHE) by applying a single $\mathrm{Si}_{3} \mathrm{~N}_{4}$ dielectric layer. We then employed different $\mathrm{Al}_{2} \mathrm{O}_{3}$ dielectric layer thicknesses on top of the $\mathrm{Si}_{3} \mathrm{~N}_{4}$ and analyzed the lattice temperature across the 2-DEG channel layer to verify the thermal effect on the gate leakage current. Finally, we discuss an optimized MIS-HEMT structure as a normally-on device.

\section{Materials and Methods}

This study analyzed and compared MIS-HEMT transfer I-V characteristics for different dielectric layer compositions and thicknesses, as shown in Figure 1. Figure 1a,b shows schematic views of a basic AlGaN/GaN-based HEMT (BG-HEMT) and MIS-HEMT, respectively. Figure 1c represents the composition and thickness of distinct dielectric layers A, B, and C. Table 1 summarizes the BG-HEMT layer information, where the nominal Al composition of the AlGaN layer was $26 \%$.

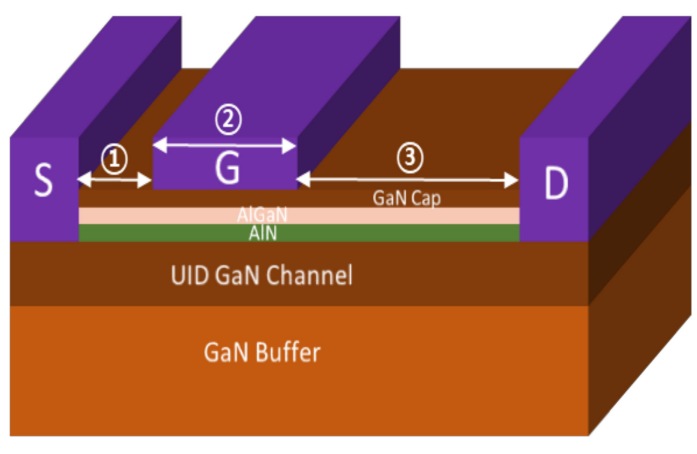

(a)

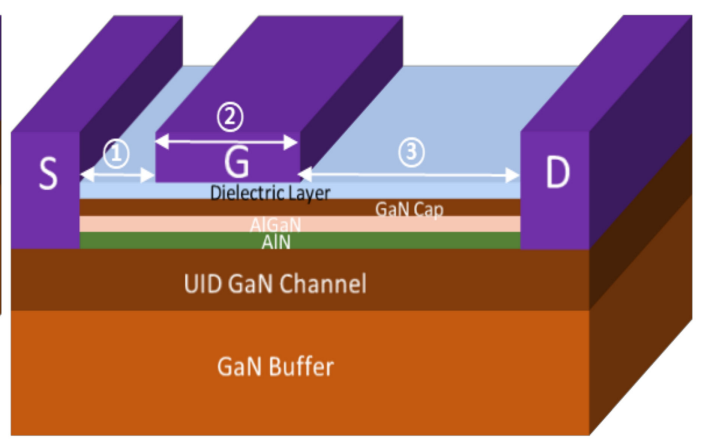

(b)

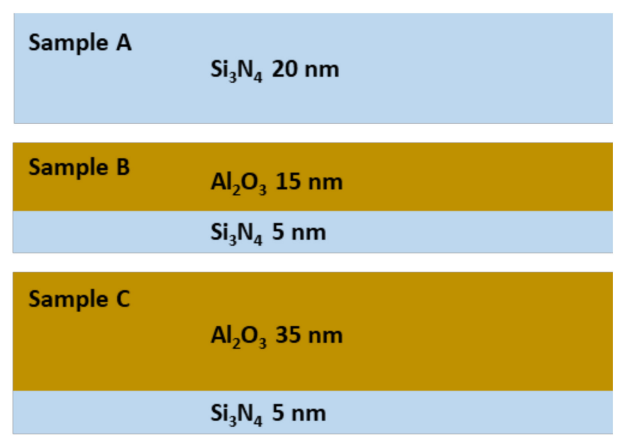

(c)

Figure 1. Basic AlGaN/GaN-based MIS-HEMT (a) without and (b) with a dielectric layer, and (c) dielectric layer composition and thickness for samples A, B, and C. 
Table 1. Basic AlGaN/GaN-based HEMT geometrical parameters.

\begin{tabular}{cc}
\hline Parameter & Value \\
\hline (1) $L_{S G}$ & $1.0 \mu \mathrm{m}$ \\
(2) $L_{G}$ & $4.5 \mu \mathrm{m}$ \\
(3) $L_{G D}$ & $9.5 \mu \mathrm{m}$ \\
GaN Cap & $2.0 \mathrm{~nm}$ \\
AlGaN & $21 \mathrm{~nm}$ \\
AlN & $1.0 \mathrm{~nm}$ \\
UID GaN Channel & $0.1 \mu \mathrm{m}$ \\
GaN Buffer & $1.8 \mu \mathrm{m}$ \\
\hline
\end{tabular}

We used two gate leakage current models to compare the BG-HEMT and MIS-HEMT structures' gate leakage currents. Figure 2a depicts the Poole-Frenkel thermal emission (PF) mechanism principle. Crystalline mismatches between layers when fabricating AlGaN/GaN HEMTs cause trap and continuum energy states in the barrier material. Electrons captured in trap energy states move to continuum energy states via high electric fields and temperatures, and current is generated by the voltage drop in the high reverse gate voltages. Figure $2 b$ shows the Fowler-Nordheim tunneling (FN) mechanism. The barrier becomes thinner under high electric fields, allowing more electrons to penetrate the barrier and generate a current at high forward gate voltages [23-25]. The interface trap between the insulator and semiconductor is inevitable while growing epitaxial layers and causes the 2-DEG concentration and threshold voltage to become unstable. Therefore, it is essential to consider the interface trap density [26,27]. To obtain more accurate data, we set the interface trap density at the dielectric layer/GaN cap interface and acceptor trap density in the $\mathrm{GaN}$ buffer layer. Figure 3a shows the interface trap density at the $\mathrm{Si}_{3} \mathrm{~N}_{4} / \mathrm{GaN}$ cap interface $=2.1 \times 10^{12} \mathrm{~cm}^{-2}$, and Figure $3 \mathrm{~b}$ shows acceptor trap density doping profile in $\mathrm{GaN}$ buffer layer $=2.09 \times 10^{15} \mathrm{~cm}^{-3}$ at the unintentionally doped (UID) GaN/GaN buffer interface [28].

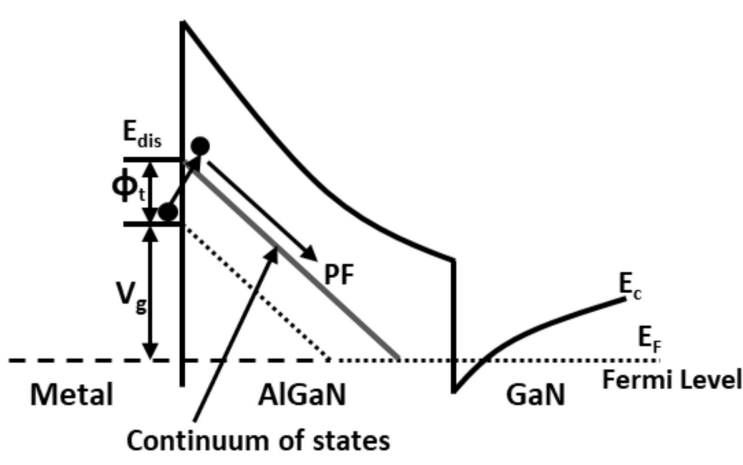

(a)

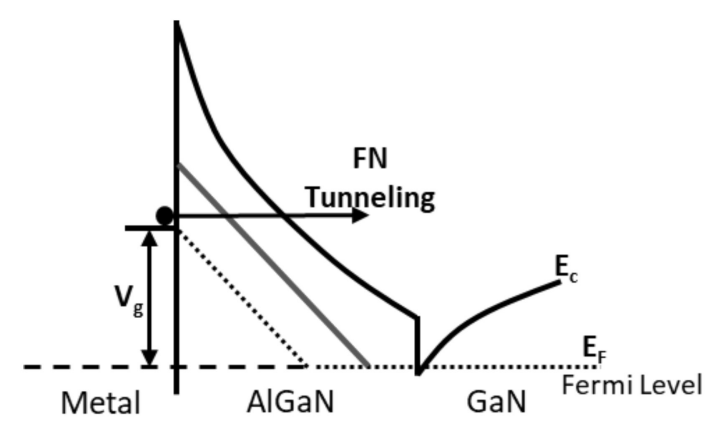

(b)

Figure 2. Mechanism of gate leakage current models: (a) Poole-Frenkel thermal emission, and (b) Fowler-Nordheim tunneling. 


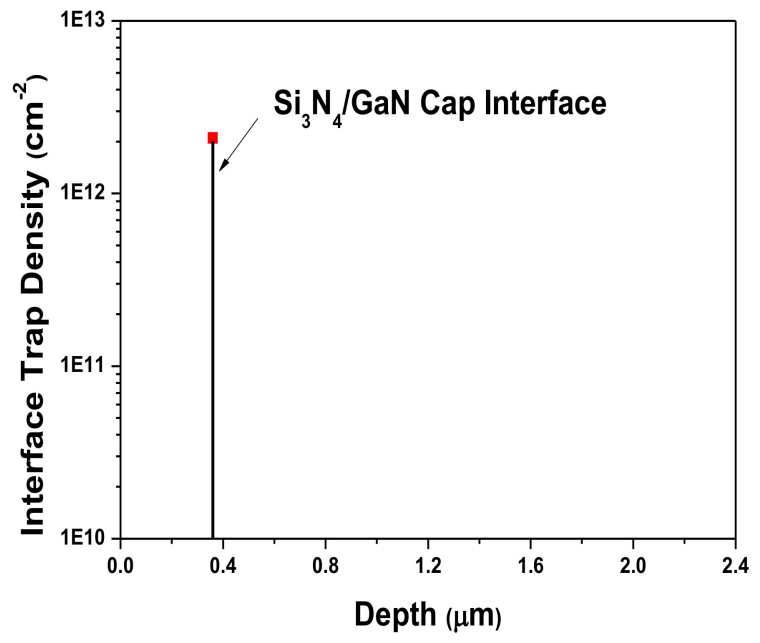

(a)

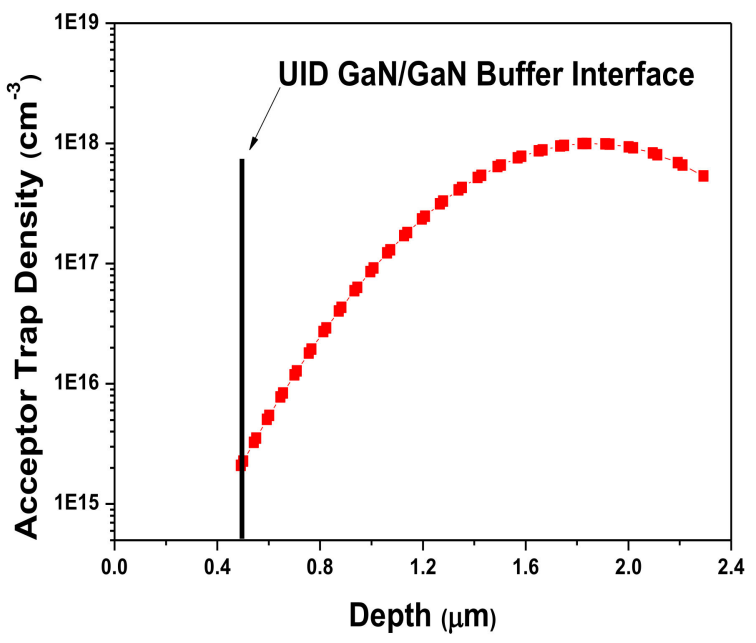

(b)

Figure 3. (a) Interface trap density at the $\mathrm{Si}_{3} \mathrm{~N}_{4} / \mathrm{GaN}$ cap interface, and (b) GaN buffer layer acceptor trap density doping profile with respect to depth.

Since the thermal conductivity of the material affects the heat transfer during operation of the device and depends on the temperature, the lattice heat flow based on the thermal conductivity model is essential to considering SHE [29]. The thermal conductivity model is given by:

$$
k\left(T_{L}\right)=(\text { TC.CONST }) /\left(\frac{T_{L}}{300}\right)^{T C . N P O W}
$$

where TC.CONST, $T_{L}$, and TC.NPOW are the thermal conductivity constant at $300 \mathrm{~K}$, local lattice temperature, and coefficient of temperature dependence of thermal conductivity, respectively. As shown in Table 2, thermal conductivity constants of GaN and AlGaN were applied. Then, the lattice heat flow model is applied by using the calculated thermal conductivity, and it can be expressed as

$$
C \frac{\partial T_{L}}{\partial t}=\nabla\left(k \nabla T_{L}\right)+H
$$

where $C, k, H$, and $T_{L}$ are the heat capacitance per unit volume, thermal conductivity, heat generation, and local lattice temperature, respectively. $k$ is calculated using Equation (1), and $H$ is expressed as:

$$
\begin{gathered}
H=\frac{\left|\overrightarrow{J_{n}}\right|^{2}}{q \mu_{n} n}+\frac{\left|\overrightarrow{J_{p}}\right|^{2}}{q \mu_{p} p}-T_{L}\left(\overrightarrow{J_{n}} \nabla P_{n}\right)-T_{L}\left(\overrightarrow{J_{p}} \nabla P_{p}\right) \\
+q(R-G)\left[T_{L}\left[\frac{\partial \varphi_{n}}{\partial T}\right]_{n \cdot p}-\varphi_{n}-\left[\frac{\partial \varphi_{p}}{\partial T}\right]_{n \cdot p}+\varphi_{p}\right] \\
-T_{L}\left[\left[\frac{\partial \varphi_{n}}{\partial T}\right]_{n . p}+P_{n}\right] d i v J_{n}-T_{L}\left[\left[\frac{\partial \varphi_{p}}{\partial T}\right]_{n . p}+P_{p}\right] d i v J_{p}
\end{gathered}
$$

In the steady-state, the current divergence can be replaced by the net recombination. Equation (3) then simplifies to:

$$
H=\left[\frac{\left|\overrightarrow{J_{n}}\right|^{2}}{q \mu_{n} n}+\frac{\left|\overrightarrow{J_{p}}\right|^{2}}{q \mu_{p} p}\right]+q(R-G)\left[\varphi_{p}-\varphi_{n}+T_{L}\left[P_{p}-P_{n}\right]\right]-T_{L}\left(\overrightarrow{J_{n}} \nabla P_{n}+\overrightarrow{J_{p}} \nabla P_{p}\right)
$$


where $\left[\frac{\left|\overrightarrow{J_{n}}\right|^{2}}{q \mu_{n} n}+\frac{\left|\overrightarrow{I_{p}}\right|^{2}}{q \mu_{p} p}\right]$ is the Joule heating effect term, $q(R-G)\left[\varphi_{p}-\varphi_{n}+T_{L}\left[P_{p}-P_{n}\right]\right]$ is the heating and cooling term considering recombination and generation, and $-T_{L}\left(\overrightarrow{J_{n}} \nabla P_{n}+\overrightarrow{J_{p}} \nabla P_{p}\right)$ accounts for the Peltier and Joule-Thomson effects. A simple and intuitive form of $H$ that has been widely used in the past is:

$$
H=\left(\overrightarrow{J_{n}}+\overrightarrow{J_{p}}\right) \cdot \vec{E}
$$

where $H$ is the generated heat, $\vec{J}_{n}$ and $\overrightarrow{J_{p}}$ are electron and hole current densities, respectively, and $\vec{E}$ is the electric field. SHE can be estimated using either Equation (4) or (5) for steady-state calculations. By default, Equation (5) is used.

We set the work function of the gate, source, and drain metals for Schottky and ohmic contacts, respectively. However, in the case of MIS-HEMT, the work function changes because of dielectric layers, even if the work function of the gate metal is fixed. This is due to the high- $k$ effective work function model, which is expressed as:

$$
\Phi_{\text {meff }}=E_{\text {highk }}+S_{\text {highk }}\left(\Phi_{m}-E_{\text {highk }}\right)
$$

where $\Phi_{m e f f}$ is the effective gate work function, $E_{\text {highk }}$ is the high- $k$ material charge neutrality, $S_{\text {highk }}$ is a slope parameter of the high- $k$ material, and $\Phi_{m}$ is the metal work function in a vacuum $\left(\Phi_{m}=3.73 \mathrm{eV}\right.$ for a Schottky contact [30]).

We considered auger recombination, Schockley-Read-Hall recombination, strain piezoelectric polarization, Selberherr's impact ionization model, self-heating, thermal conductivity, the Fermi-Dirac distribution function, Poole-Frenkel thermal emission, the Fowler-Nordheim tunneling model, and the high- $k$ effective work function model for the physical calculations [31-34]. Table 2 shows AlGaN and $\mathrm{GaN}$ material parameters.

Figure 4 shows the thermal conductivities of $\mathrm{GaN}, \mathrm{Al}_{2} \mathrm{O}_{3}$, and $\mathrm{Si}_{3} \mathrm{~N}_{4}$ as a function of temperature. As temperature increases above $400 \mathrm{~K}$, the thermal conductivity of $\mathrm{Al}_{2} \mathrm{O}_{3}$ becomes lower than that for $\mathrm{Si}_{3} \mathrm{~N}_{4}$.

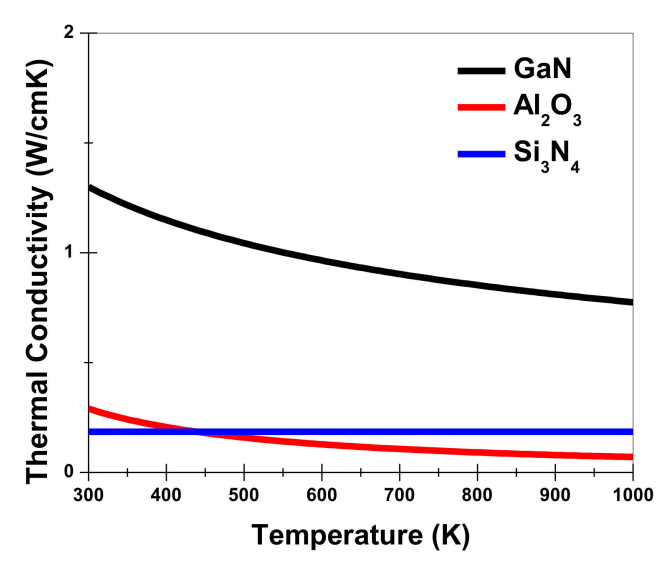

Figure 4. Thermal conductivities for $\mathrm{GaN}, \mathrm{Al}_{2} \mathrm{O}_{3}$, and $\mathrm{Si}_{3} \mathrm{~N}_{4}$ with respect to temperature.

\section{Results and Discussion}

We first compared BG-HEMT and MIS-HEMT (sample A) transfer I-V characteristics for each drain voltage $\left(\mathrm{V}_{\mathrm{DS}}\right)=1,5,10$, and $30 \mathrm{~V}$. The sample $\mathrm{A}$ threshold voltage shifted negatively to reach approximately $-7.5 \mathrm{~V}$, and the maximum transconductance decreased compared with BG-HEMT, as shown in Figure 5. The sample A drain current was generally larger than that for BG-HEMT and became much larger as $\mathrm{V}_{\mathrm{DS}}$ increased. 


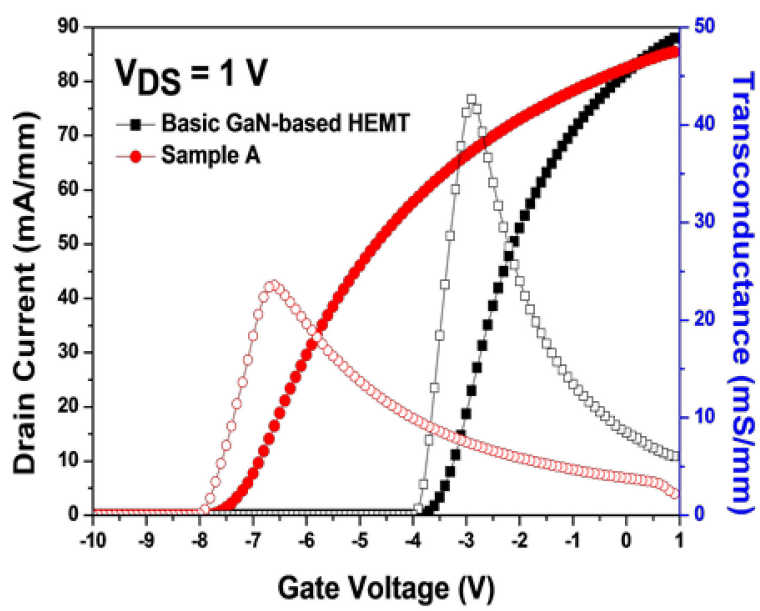

(a)

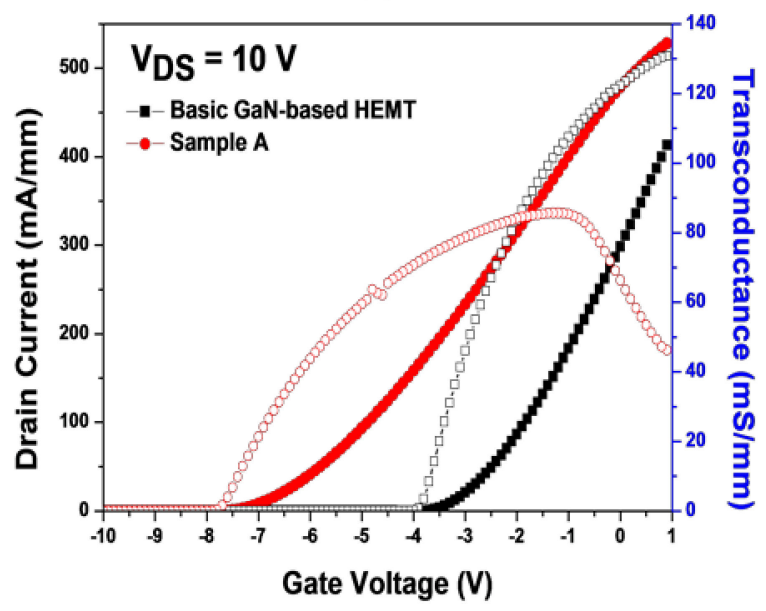

(c)

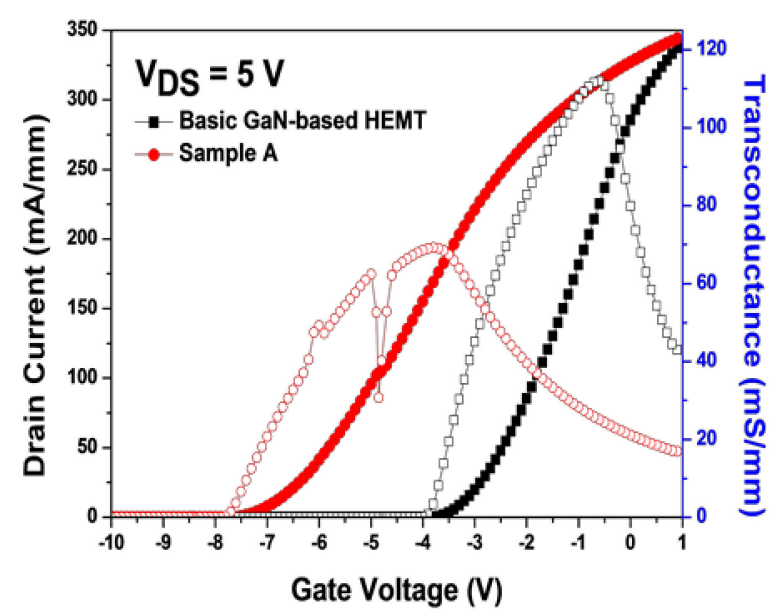

(b)

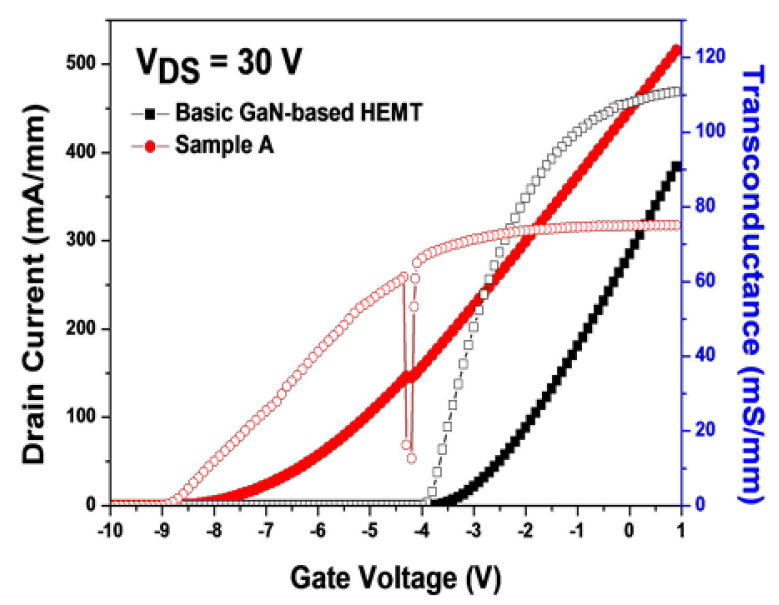

(d)

Figure 5. Transfer I-V characteristics for BG-HEMT and MIS-HEMT (sample A) at (a) $\mathrm{V}_{\mathrm{DS}}=1 \mathrm{~V}$, (b) $\mathrm{V}_{\mathrm{DS}}=5 \mathrm{~V},(\mathbf{c}) \mathrm{V}_{\mathrm{DS}}=10 \mathrm{~V}$, and (d) $\mathrm{V}_{\mathrm{DS}}=30 \mathrm{~V}$ (drain current (filled dot), transconductance (empty dot)).

Figure 6 shows the measured gate leakage current with respect to the gate voltage $\left(\mathrm{V}_{\mathrm{GS}}\right)$ for $\mathrm{V}_{\mathrm{DS}}$ $=1,5,10$, and $30 \mathrm{~V}$. In the case of BG-HEMT, the gate leakage current decreased as $\mathrm{V}_{\mathrm{GS}}$ increased at low $\mathrm{V}_{\mathrm{DS}}=1$ and $5 \mathrm{~V}$. However, at high $\mathrm{V}_{\mathrm{DS}}=10$ and $30 \mathrm{~V}$, the gate leakage current decreased with increasing $\mathrm{V}_{\mathrm{GS}}$, but increased again. The gate leakage current was affected by heat, and when $\mathrm{V}_{\mathrm{GS}}$ was above the threshold voltage of about $-3.7 \mathrm{~V}$, the gate leakage current increased because heat was generated by the device operation. In contrast, the gate leakage current was significantly reduced in sample A.

Figure 7 shows the lattice temperature and electric field across the 2-DEG channel layer of the BG-HEMT and sample $A$ at $V_{G S}=0 \mathrm{~V}$ and $V_{D S}=30 \mathrm{~V}$. Sample A's lattice temperature in the 2-DEG channel layer was significantly higher than that for BG-HEMT, but sample A's electric field was lower than that for BG-HEMT. Since the increase of current density was larger (see Figure $5 \mathrm{~d}$ ) than the decrease of the electric field in sample A, as shown in Figure $7 \mathrm{~b}$, the overall lattice temperature of sample A across the 2-DEG channel layer was larger than that of BG-HEMT, as shown in Figure 7a (see Equation (5)). Although the gate leakage current can be affected by temperature, the dielectric layer effectively reduced the gate leakage current [21]. 


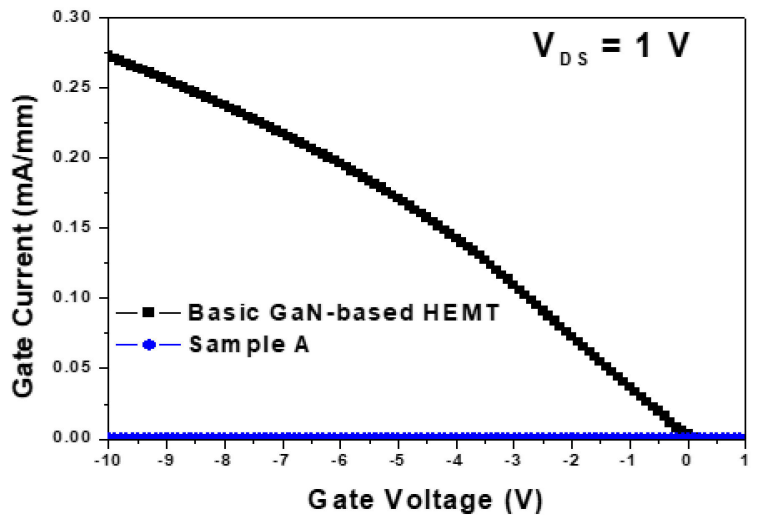

(a)

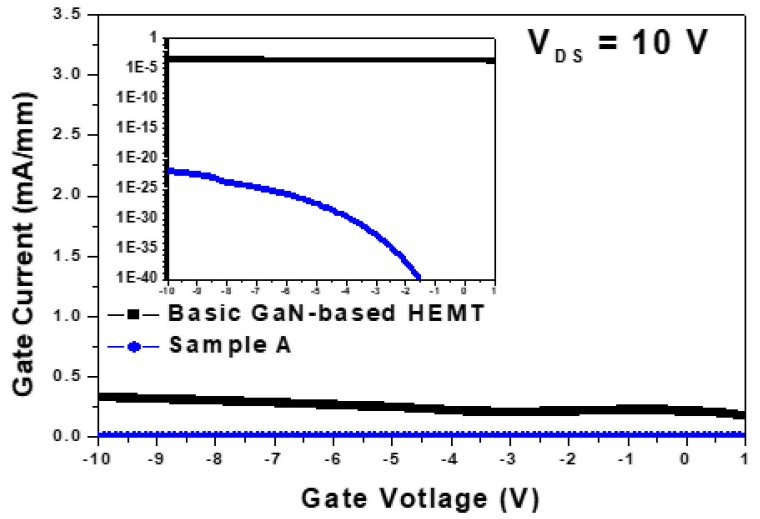

(c)

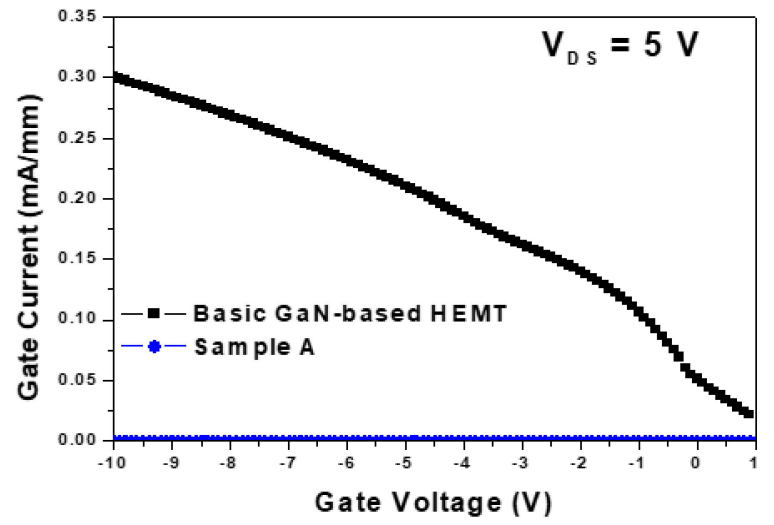

(b)

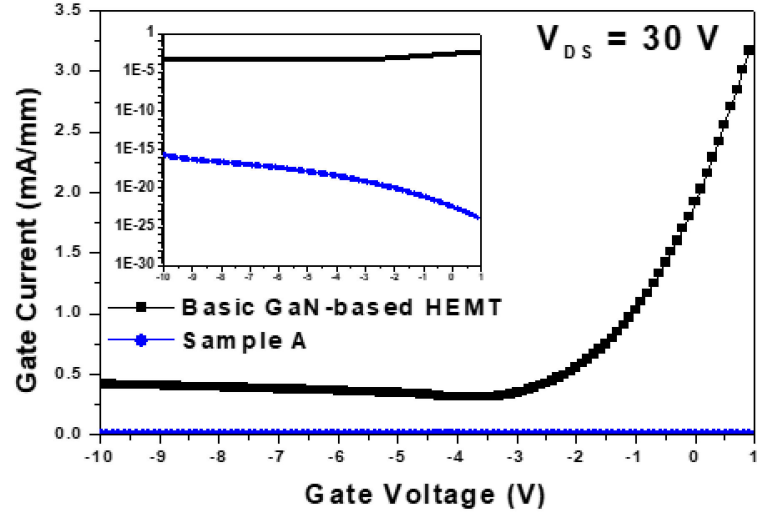

(d)

Figure 6. Gate leakage current for BG-HEMT and MIS-HEMT (sample A) with respect to $\mathrm{V}_{\mathrm{GS}}$ at (a) $\mathrm{V}_{\mathrm{DS}}=1 \mathrm{~V},(\mathbf{b}) \mathrm{V}_{\mathrm{DS}}=5 \mathrm{~V}$, (c) $\mathrm{V}_{\mathrm{DS}}=10 \mathrm{~V}$, and (d) $\mathrm{V}_{\mathrm{DS}}=30 \mathrm{~V}$.

Table 2. Material parameters used for simulations at temperature $300 \mathrm{~K}$.

\begin{tabular}{ccc}
\hline Parameter & GaN & AlGaN \\
\hline Bandgap energy $(\mathrm{eV})$ & 3.39 & 3.89 \\
Electron affinity $(\mathrm{eV})$ & 4 & 3.6 \\
Low field mobility $\left(\mathrm{cm}^{2} \mathrm{~V}^{-1} \mathrm{~s}^{-1}\right)$ & 990 & 300 \\
Relative permittivity & 9.5 & 9.38 \\
Thermal conductivity constant $\left(\mathrm{W} \mathrm{cm}^{-1} \mathrm{~K}^{-1}\right)$ & 1.3 & 0.4 \\
TC.NPOW & 0.43 & - \\
High field mobility model & GANSAT saturation velocity model \\
Electron Saturation velocity $\left(\mathrm{cm} \mathrm{s}^{-1}\right)$ & $1.9 \times 10^{7}$ & $1.12 \times 10^{7}$ \\
\hline
\end{tabular}

After confirming that sample A's gate leakage current was markedly reduced, the dielectric layer composition was changed, as shown in Figure 1c. We then compared the transfer I-V characteristics for these structures when $V_{\mathrm{DS}}=1,5,10$, and $30 \mathrm{~V}$. Figure 8 shows the threshold voltages, maximum transconductances, and drain currents for samples A, B, and C. Sample B's threshold voltage shifted toward the positive direction as compared with sample $\mathrm{A}$, and sample $\mathrm{C}$ shifted toward the negative direction [35]. Sample B and C's threshold voltages were about -6.2 and $-9.4 \mathrm{~V}$, respectively. Maximum transconductance was achieved for sample B, then $C$ and $A$, in descending order. However, the drain current exhibited different tendencies, with sample $C$ obtaining the highest value, then sample $B$ and $\mathrm{A}$, in descending order. 


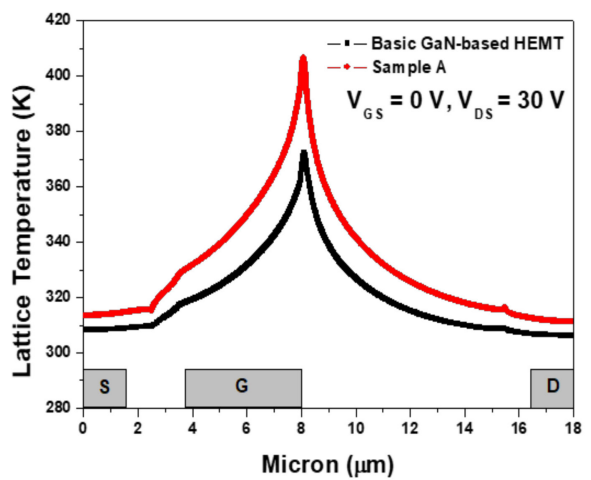

(a)

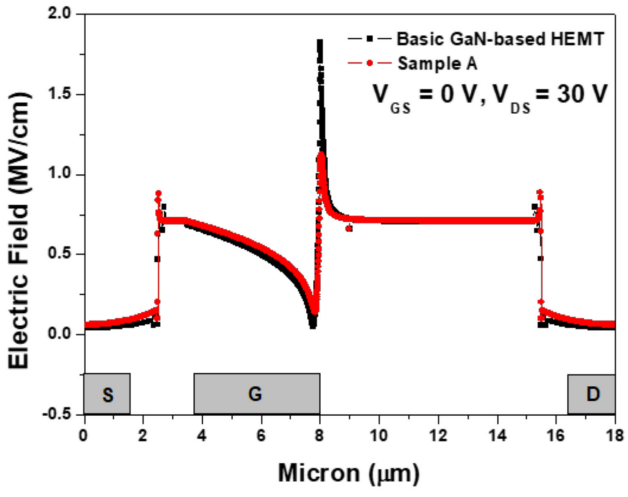

(b)

Figure 7. (a) Lattice temperature, and (b) electric field distributions across the 2-DEG channel layer with and without the $\mathrm{Si}_{3} \mathrm{~N}_{4}$ dielectric layer at $\mathrm{V}_{\mathrm{GS}}=0 \mathrm{~V}$ and $\mathrm{V}_{\mathrm{DS}}=30 \mathrm{~V}$.

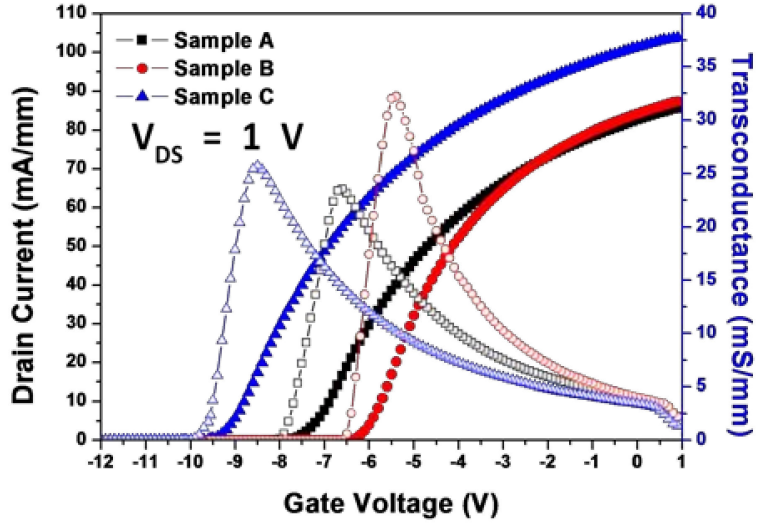

(a)

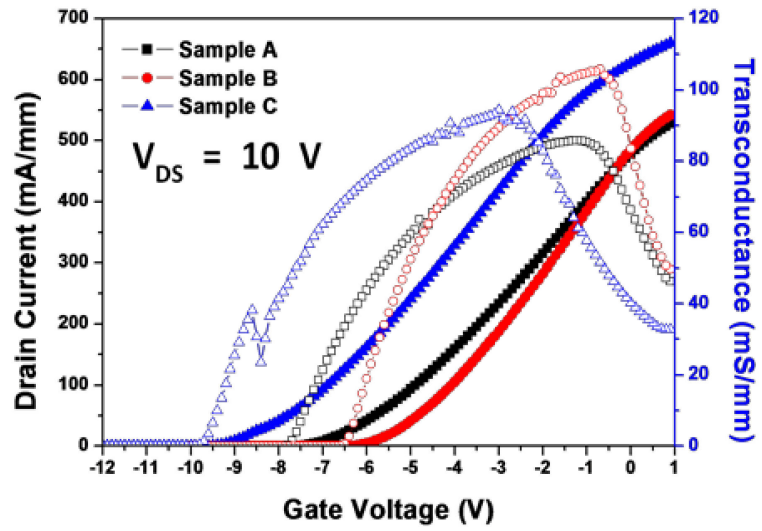

(c)

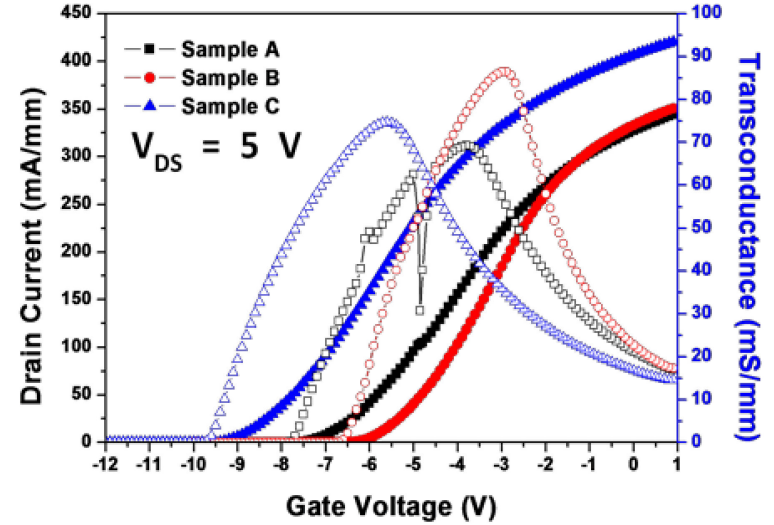

(b)

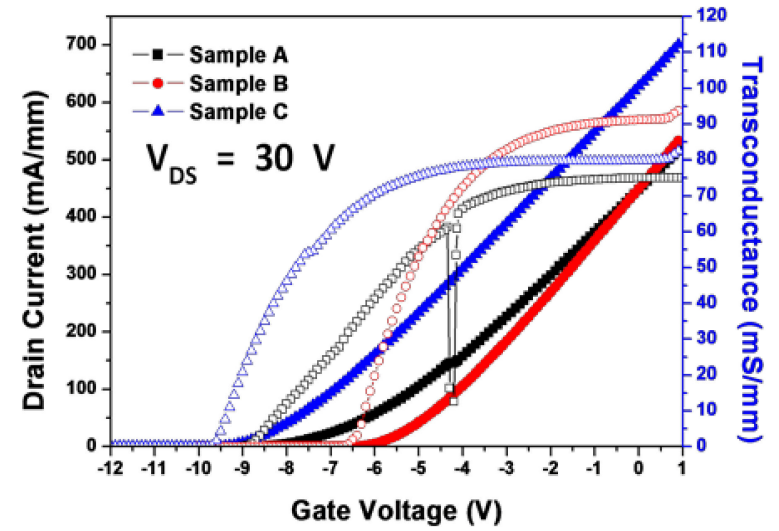

(d)

Figure 8. Comparison of transfer I-V characteristics of MIS-HEMTs (samples A, B, and C) with respect to $\mathrm{V}_{\mathrm{GS}}$ at $(\mathbf{a}) \mathrm{V}_{\mathrm{DS}}=1 \mathrm{~V},(\mathbf{b}) \mathrm{V}_{\mathrm{DS}}=5 \mathrm{~V}$, (c) $\mathrm{V}_{\mathrm{DS}}=10 \mathrm{~V}$, and (d) $\mathrm{V}_{\mathrm{DS}}=30 \mathrm{~V}$ (drain current (filled dot), transconductance (empty dot)).

Samples A, B, and C's gate leakage currents were simulated at high $\mathrm{V}_{\mathrm{DS}}=10$ and $30 \mathrm{~V}$. Figure 9 shows that sample B's gate leakage current was significantly reduced compared with sample A, even though the values were extremely low. Since the actual physical phenomena occurring in the device were not known, the results only represented the tendency of the gate leakage current depending on 
the dielectric layer composition and thickness. Sample C's gate leakage current exceeded sample B's. Thus, $\mathrm{Al}_{2} \mathrm{O}_{3}$ deposition on $\mathrm{Si}_{3} \mathrm{~N}_{4}$ effectively reduced the gate leakage current, but the gate leakage current increased with thicker $\mathrm{Al}_{2} \mathrm{O}_{3}$ on $\mathrm{Si}_{3} \mathrm{~N}_{4}$.

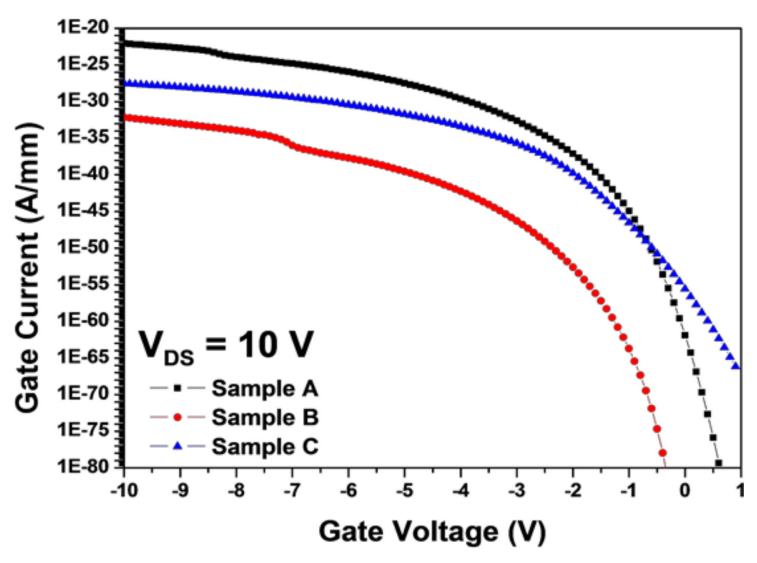

(a)

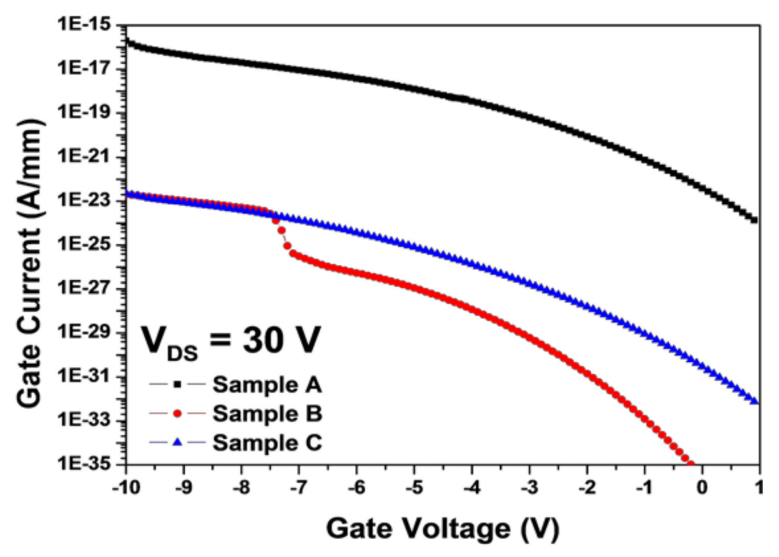

(b)

Figure 9. Gate leakage current for MIS-HEMTs (samples A, B, and C) with respect to $\mathrm{V}_{\mathrm{GS}}$ at (a) $\mathrm{V}_{\mathrm{DS}}=10 \mathrm{~V}$ and $(\mathbf{b}) \mathrm{V}_{\mathrm{DS}}=30 \mathrm{~V}$.

Figure 10a shows that sample C's lattice temperature across the 2-DEG channel layer was the highest, with samples $A$ and $B$ exhibiting similar values when $V_{G S}=0 \mathrm{~V}$ and $V_{D S}=30 \mathrm{~V}$. The highest peaks occurred at the drain-side gate head edges with $441.94,406.64$, and $406.38 \mathrm{~K}$ for samples $\mathrm{C}, \mathrm{A}$, and $B$, respectively. However, the electric field distributions for the three structures were different. Sample A was the highest, followed by samples B and C at the drain-side gate head edge. As shown in Figure 5; Figure 7, sample C's lattice temperature across the 2-DEG channel layer was higher than sample B because sample C's effective current density was also higher, as shown in Figure 8. Figure 10b shows that sample $C$ exhibited an even lower electric field at the drain-side gate edge, which resulted in an increasing gate leakage current, as shown in Figure 9. As the thickness of the insulator increased, the current due to the tunneling effect decreased. However, when the thickness of the insulator increased, the threshold voltage, stress, and heat transfer must be considered. In the case of samples $\mathrm{B}$ and $\mathrm{C}$, the dielectric layer composition was a combination of $\mathrm{Al}_{2} \mathrm{O}_{3}$ and $\mathrm{Si}_{3} \mathrm{~N}_{4}$. Since the barrier height in samples $B$ and $C$ were larger than for $A$, the gate leakage current by FN tunneling was reduced. For sample $C$, the electric field was the lowest, but the current density was the highest at $V_{G S}=0 \mathrm{~V}$ and $\mathrm{V}_{\mathrm{DS}}=30 \mathrm{~V}$, resulting in generating more heat. In addition, the thermal conductivity of the materials must be taken into account in the heat transfer. The thermal conductivity of $\mathrm{Al}_{2} \mathrm{O}_{3}$ was lower than that of $\mathrm{Si}_{3} \mathrm{~N}_{4}$. The induced heat confined in the $\mathrm{Al}_{2} \mathrm{O}_{3}$ further lowered the barrier height and increased the gate leakage current.

Figure 11 shows the MIS-HEMT breakdown voltage characteristics. Depositing the $\mathrm{Al}_{2} \mathrm{O}_{3}$ on the $\mathrm{Si}_{3} \mathrm{~N}_{4}$ dielectric layer improved the breakdown voltage. We set the breakdown voltage for the drain current $=1 \mathrm{~mA} / \mathrm{mm}$ as a reference, and achieved breakdown voltage values that were about 94, 194 , and $300 \mathrm{~V}$ at pinch-off voltages $=-14,-12$, and $-12.6 \mathrm{~V}$, respectively, considering each threshold voltage. Although the gate leakage current in sample $C$ was larger than for sample $B$, it showed higher breakdown characteristics. 


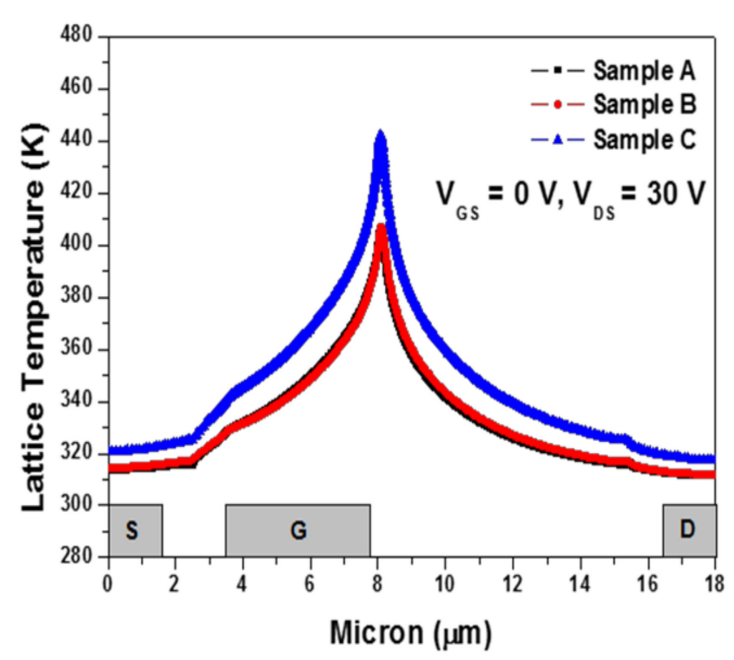

(a)

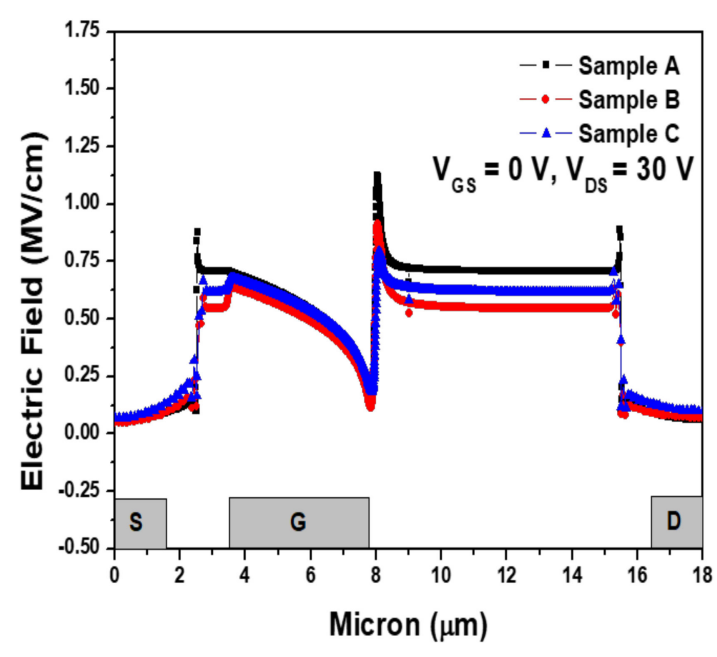

(b)

Figure 10. (a) Lattice temperature, and (b) electric field distributions across 2-DEG channel layer for MIS-HEMTs (samples A, B, and C) at $\mathrm{V}_{\mathrm{GS}}=0 \mathrm{~V}$, and $\mathrm{V}_{\mathrm{DS}}=30 \mathrm{~V}$.

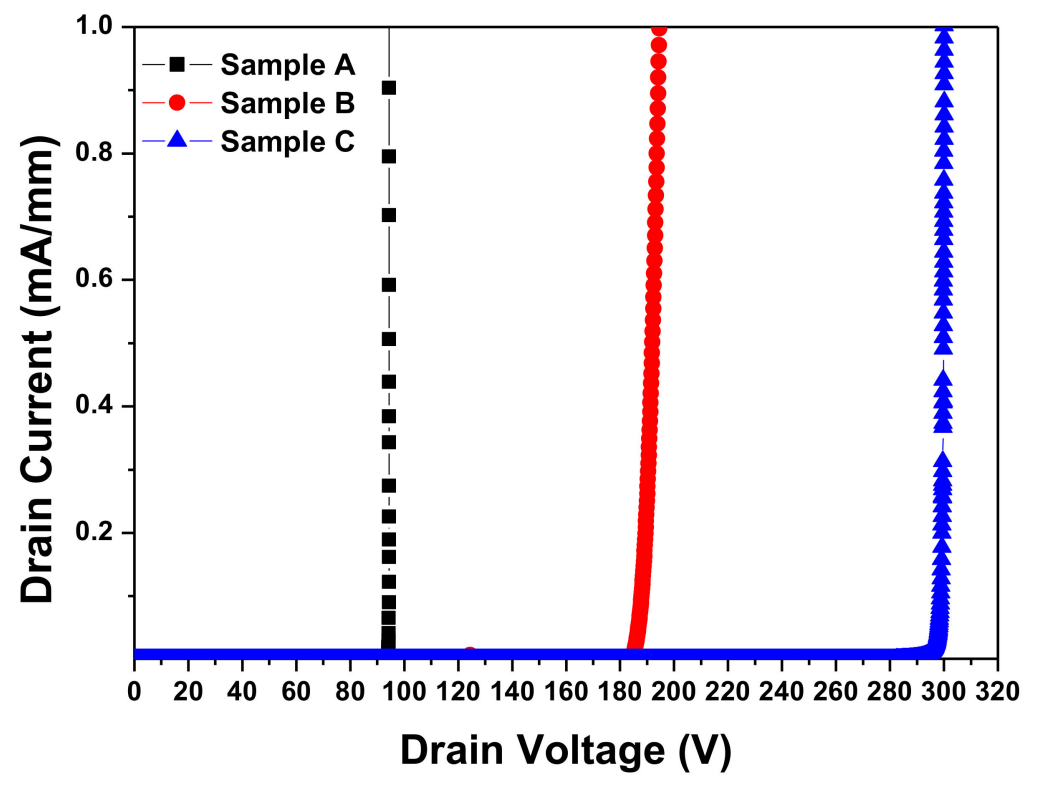

Figure 11. Breakdown voltage characteristics for MIS-HEMTs (samples A, B, and C).

Figure 12 shows the MIS-HEMT saturation current characteristics with and without SHE for $\mathrm{V}_{\mathrm{GS}}=-2$ to $0 \mathrm{~V}$. SHE decreased the drain current for all three structures and made the current unstable. Sample C was more affected by SHE and sample B was less affected. Table 3 shows the calculated level of drain current degradation for all three structures. Although sample $C$ had a higher breakdown voltage and drain current, the gate leakage current was higher and the drain current was more affected by SHE. Therefore, an appropriate $\mathrm{Al}_{2} \mathrm{O}_{3}$ thickness on $\mathrm{Si}_{3} \mathrm{~N}_{4}$ is crucial to operating an $\mathrm{AlGaN} / \mathrm{GaN}$ HEMT as a normally-on device. 


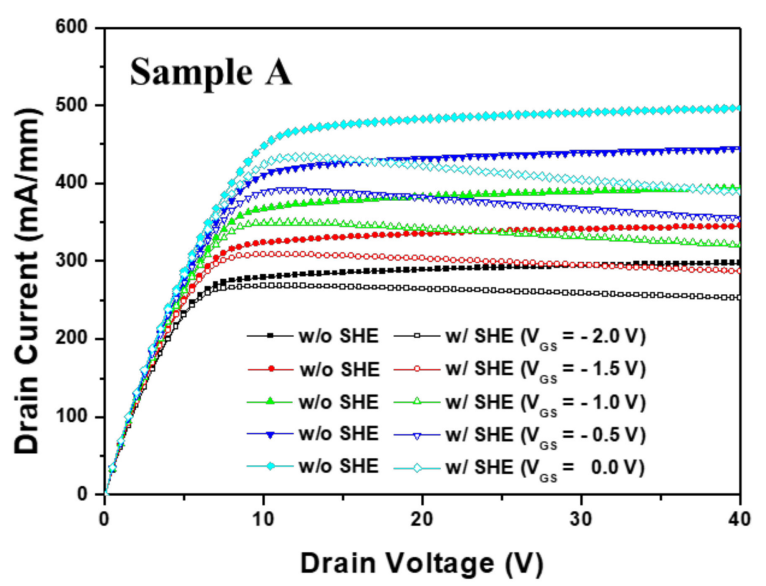

(a)

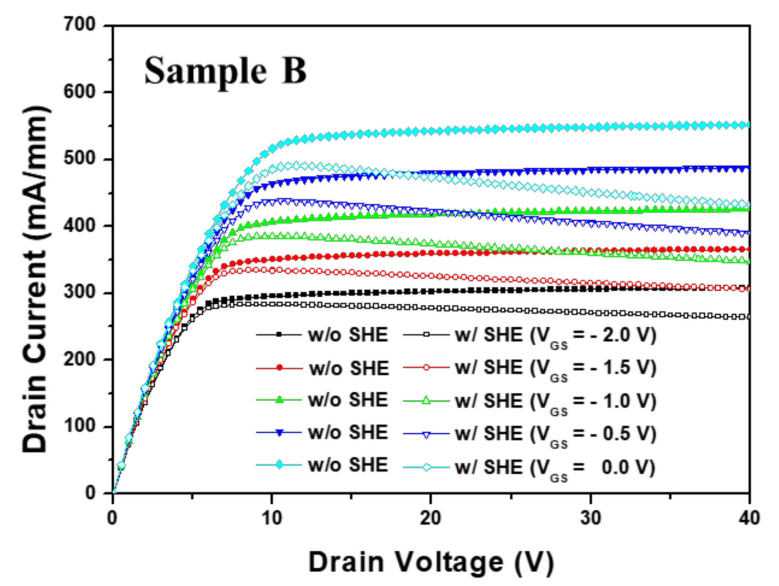

(b)

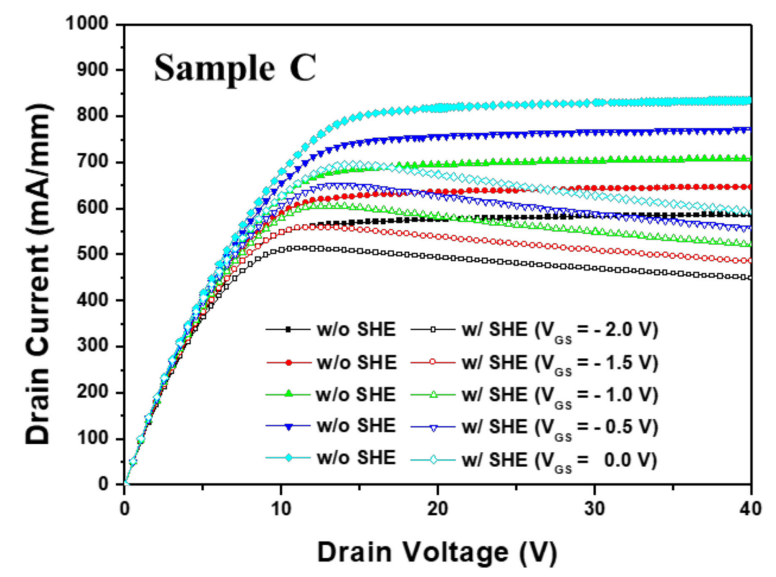

(c)

Figure 12. Saturation current characteristics for MIS-HEMT with and without the self-heating effect (SHE) as a normally-on device: (a) sample A, (b) sample B, and (c) sample C.

Table 3. Drain current variation due to the self-heating effect.

\begin{tabular}{|c|c|c|c|c|c|}
\hline \multirow{2}{*}{ Type } & \multicolumn{5}{|c|}{$\Delta \mathrm{I}_{\mathrm{D}}(\mathrm{mA} / \mathrm{mm})\left(\right.$ at $\left.\mathrm{V}_{\mathrm{DS}}=40 \mathrm{~V}\right)$} \\
\hline & $\mathrm{V}_{\mathrm{GS}}=-2.0 \mathrm{~V}$ & $\mathrm{~V}_{\mathrm{GS}}=-1.5 \mathrm{~V}$ & $\mathrm{~V}_{\mathrm{GS}}=-1.0 \mathrm{~V}$ & $\mathrm{~V}_{\mathrm{GS}}=-0.5 \mathrm{~V}$ & $\mathrm{~V}_{\mathrm{GS}}=0.0 \mathrm{~V}$ \\
\hline $\mathbf{A}$ & -45.17 & -58.38 & -73.23 & -89.49 & -107.41 \\
\hline B & -44.49 & -60.10 & -77.99 & -98.01 & -119.92 \\
\hline $\mathrm{C}$ & -138.17 & -161.87 & -187.07 & -213.58 & -241.27 \\
\hline
\end{tabular}

\section{Conclusions}

This study provides a simulation study of transfer I-V characteristics, gate leakage current, and saturation current characteristics for MIS-HEMT structures by considering SHE. The gate leakage current increased with increasing temperature, but the MIS-HEMT gate leakage current was significantly lower than the basic AlGaN/GaN-based HEMT, even when temperature was increased by applying the gate dielectric layer. The gate dielectric layer, consisting of $\mathrm{Si}_{3} \mathrm{~N}_{4}$ and $\mathrm{Al}_{2} \mathrm{O}_{3}$, reduced the gate leakage current more than a single $\mathrm{Si}_{3} \mathrm{~N}_{4}$ gate dielectric layer did. However, the threshold voltage, gate leakage current, and breakdown voltage all changed depending on the dielectric layer composition and thickness. The MIS-HEMT gate leakage current and breakdown voltage with $\mathrm{Al}_{2} \mathrm{O}_{3}$ on $\mathrm{Si}_{3} \mathrm{~N}_{4}$ were significantly improved compared with the device incorporating only $\mathrm{Si}_{3} \mathrm{~N}_{4}$. However, the saturation current characteristics became too unstable to operate as a normally-on device for thicker $\mathrm{Al}_{2} \mathrm{O}_{3}$ layers. 
Future work will study MIS-HEMT structures in more detail, with wider ranges of dielectric layer compositions and thicknesses.

Author Contributions: Experiments and simulations, I.-T.H., K.-W.J., and H.-J.K.; fabrication, S.-H.L. and J.-W.L.; formal analysis, J.-M.Y. and H.-S.K. (Ho-Sang Kwon); supervision, H.-S.K. (Hyun-Seok Kim).

Funding: This work was supported by the program of Defense Acquisition Program Administration and Agency for Defense Development.

Conflicts of Interest: The authors declare no competing financial interests.

\section{References}

1. Mishra, U.K.; Parikh, P.; Wu, Y.F. AlGaN/GaN HEMTs-an overview of device operation and applications. Proc. IEEE 2002, 90, 1022-1031. [CrossRef]

2. Mishra, U.K.; Shen, L.; Kazior, T.E.; Wu, Y.F. GaN-based RF power devices and amplifiers. Proc. IEEE 2008, 96, 287-305. [CrossRef]

3. Ambacher, O.; Foutz, B.; Smart, J.; Shealy, J.R.; Weimann, N.G.; Chu, K.; Murphy, M.; Sierakowski, A.J.; Schaff, W.J.; Eastman, L.F.; et al. Two dimensional electron gases induced by spontaneous and piezoelectric polarization in undoped and doped AlGaN/GaN heterostructures. J. Appl. Phys. 2000, 87, 334-344. [CrossRef]

4. Chung, J.W.; Roberts, J.C.; Piner, E.L.; Palacios, T. Effect of gate leakage in the subthreshold characteristics of AlGaN/GaN HEMTs. IEEE Electron Device Lett. 2008, 29, 1196-1198. [CrossRef]

5. Kim, H.; Lee, J.; Liu, D.; Lu, W. Gate current leakage and breakdown mechanism in unpassivated AlGaN/GaN high electron mobility transistors by post-gate annealing. Appl. Phys. Lett. 2005, 86, 143505. [CrossRef]

6. Park, Y.J.; Kwak, H.T.; Chang, S.B.; Kim, H.S. Breakdown Voltage Enhancement in AlGaN/GaN High-Electron Mobility Transistor by Optimizing Gate Field-Plate Structure. J. Nanosci. Nanotechnol. 2019, 19, 2298-2301. [CrossRef] [PubMed]

7. Arulkumaran, S.; Egawa, T.; Ishikawa, H.; Jimbo, T. Temperature dependence of gate-leakage current in AlGaN/GaN high-electron-mobility transistors. Appl. Phys. Lett. 2003, 82, 3110-3112. [CrossRef]

8. Yan, D.; Lu, H.; Cao, D.; Chen, D.; Zhang, R.; Zheng, Y. On the reverse gate leakage current of AlGaN/GaN high electron mobility transistors. Appl. Phys. Lett. 2010, 97, 153503. [CrossRef]

9. Wang, A.; Zeng, L.; Wang, W. Simulation of Gate Leakage Current of AlGaN/GaN HEMTs: Effects of the Gate Edges and Self-Heating. ECS J. Solid State Sci. Technol. 2017, 6, 3025-3029. [CrossRef]

10. Kwak, H.T.; Chang, S.B.; Kim, H.J.; Jang, K.W.; Yoon, H.; Lee, S.H.; Lim, J.W.; Kim, H.S. Operational Improvement of AlGaN/GaN High Electron Mobility Transistor by an Inner Field-Plate Structure. Appl. Sci. 2018, 8, 974. [CrossRef]

11. Ye, G.; Wang, H.; Arulkumaran, S.; Ng, G.I.; Hofstetter, R.; Li, Y.; Anand, M.J.; Ang, K.S.; Maung, Y.K.Y.; Foo, S.C. Atomic layer deposition of $\mathrm{ZrO}_{2}$ as gate dielectrics for AlGaN/GaN metal-insulator-semiconductor high electron mobility transistors on silicon. Appl. Phys. Lett. 2013, 103, 142109. [CrossRef]

12. Zhu, J.J.; Ma, X.H.; Xie, Y.; Hou, B.; Chen, W.W.; Zhang, J.C.; Hao, Y. Improved interface and transport properties of AlGaN/GaN MIS-HEMTs with PEALD-grown AIN gate dielectric. IEEE Trans. Electron Devices 2014, 62, 512-518.

13. Chou, P.C.; Chen, S.H.; Hsieh, T.E.; Cheng, S.; Del Alamo, J.; Chang, E. Evaluation and reliability assessment of GaN-on-Si MIS-HEMT for power switching applications. Energies 2017, 10, 233. [CrossRef]

14. Yue, Y.-Z.; Hao, Y.; Feng, Q.; Zhang, J.-C.; Ma, X.-H.; Ni, J.-Y. GaN MOS-HEMT using ultra-thin $\mathrm{Al}_{2} \mathrm{O}_{3}$ dielectric grown by atomic layer deposition. Chin. Phys. Lett. 2007, 24, 2419.

15. Liu, C.; Chor, E.F.; Tan, L.S. Enhanced device performance of AlGaN/GaN HEMTs using $\mathrm{HfO}_{2}$ high-k dielectric for surface passivation and gate oxide. Semicond. Sci. Technol. 2007, 22, 522. [CrossRef]

16. Pérez-Tomás, A.; Fontserè, A.; Jennings, M.R.; Gammon, P.M. Modeling the effect of thin gate insulators ( $\mathrm{SiO}_{2}, \mathrm{SiN}, \mathrm{Al}_{2} \mathrm{O}_{3}$ and $\mathrm{HfO}_{2}$ ) on $\mathrm{AlGaN} / \mathrm{GaN}$ HEMT forward characteristics grown on $\mathrm{Si}$, sapphire and $\mathrm{SiC}$. Mater. Sci. Semicond. Process. 2013, 16, 1336-1345. [CrossRef]

17. Lu, X.; Ma, J.; Jiang, H.; Liu, C.; Xu, P.; Lau, K.M. Fabrication and Characterization of Gate-Last Self-Aligned AIN/GaN MISHEMTs WithIn SituSiN x Gate Dielectric. IEEE Trans. Electron Devices 2015, 62, 1862-1869. 
18. Kwak, H.T.; Chang, S.B.; Jung, H.G.; Kim, H.S. Thermal analysis of AlGaN/GaN high-electron-mobility transistor and its RF power efficiency optimization with source-bridged field-plate structure. J. Nanosci. Nanotechnol. 2018, 18, 5860-5867. [CrossRef]

19. Hashizume, T.; Nishiguchi, K.; Kaneki, S.; Kuzmik, J.; Yatabe, Z. State of the art on gate insulation and surface passivation for GaN-based power HEMTs. Mater. Sci. Semicond. Process. 2018, 78, 85-95. [CrossRef]

20. Lu, X.; Yu, K.; Jiang, H.; Zhang, A.; Lau, K.M. Study of interface traps in AlGaN/GaN MISHEMTs using LPCVD SiN $x$ as gate dielectric. IEEE Trans. Electron Devices 2017, 64, 824-831. [CrossRef]

21. Chang, S.J.; Jung, H.W.; Do, J.W.; Cho, K.J.; Kim, J.J.; Jang, Y.J.; Yoon, H.S.; Ahn, H.K.; Min, B.G.; Kim, H.; et al. Enhanced Carrier Transport Properties in GaN-Based Metal-Insulator-Semiconductor High Electron Mobility Transistor with $\mathrm{SiN} / \mathrm{Al}_{2} \mathrm{O}_{3}$ Bi-Layer Passivation. ECS J. Solid State Sci. Technol. 2018, 7, N86-N90. [CrossRef]

22. Silvaco, Inc. Silvaco Atlas, ver. 5.22.1.R, Semiconductor Device Modeling System. Available online: https://www.silvaco.com/products/tcad/device_simulation/atlas/atlas.html (accessed on 2 September 2019).

23. Turuvekere, S.; Karumuri, N.; Rahman, A.A.; Bhattacharya, A.; DasGupta, A.; DasGupta, N. Gate leakage mechanisms in AlGaN/GaN and AlInN/GaN HEMTs: Comparison and modeling. IEEE Trans. Electron Devices 2013, 60, 3157-3165. [CrossRef]

24. Dutta, G.; DasGupta, N.; DasGupta, A. Gate leakage mechanisms in AlInN/GaN and AlGaN/GaN MIS-HEMTs and its modeling. IEEE Trans. Electron Devices 2017, 64, 3609-3615. [CrossRef]

25. Mitrofanov, O.; Manfra, M. Poole-Frenkel electron emission from the traps in AlGaN/GaN transistors. J. Appl. Phys. 2004, 95, 6414-6419. [CrossRef]

26. Longobardi, G.; Udrea, F.; Sque, S.; Hurkx, G.A.; Croon, J.; Napoli, E.; Šonský, J. Impact of donor traps on the 2DEG and electrical behavior of AlGaN/GaN MISFETs. IEEE Electron Device Lett. 2014, 35, 27-29. [CrossRef]

27. Mehari, S.; Gavrilov, A.; Eizenberg, M.; Ritter, D. Density of traps at the insulator/III-N interface of GaN heterostructure field-effect transistors obtained by gated Hall measurements. IEEE Electron Device Lett. 2015, 36, 893-895. [CrossRef]

28. Kwak, H.T.; Jang, K.W.; Kim, H.J.; Lee, S.H.; Lim, J.W.; Kim, H.S. DC Characteristics of AlGaN/GaN High-Electron Mobility Transistor with a Bottom Plate Connected to Source-Bridged Field Plate Structure. J. Nanosci. Nanotechnol. 2019, 19, 2319-2322. [CrossRef]

29. Vitanov, S.; Palankovski, V.; Maroldt, S.; Quay, R. High-temperature modeling of AlGaN/GaN HEMTs. Solid-State Electron. 2010, 54, 1105-1112. [CrossRef]

30. Yeo, Y.C.; King, T.J.; Hu, C. Metal-dielectric band alignment and its implications for metal gate complementary metal-oxide-semiconductor technology. J. Appl. Phys. 2002, 92, 7266-7271. [CrossRef]

31. Chuang, S.L. Optical gain of strained wurtzite GaN quantum-well lasers. IEEE J. Quantum Electron. 1996, 32, 1791-1800. [CrossRef]

32. Kuzmík, J. InAlN/(In) GaN high electron mobility transistors: Some aspects of the quantum well heterostructure proposal. Semicond. Sci. Technol. 2002, 17, 540. [CrossRef]

33. Chvála, A.; Nagy, L.; Marek, J.; Priesol, J.; Donoval, D.; Blaho, M.; Gregušová, D.; Kuzmík, J.; Šatka, A. Characterization of monolithic InAIN/GaN NAND logic cell supported by circuit and device simulations. IEEE Trans. Electron Devices 2018, 65, 2666-2669. [CrossRef]

34. Selberherr, S. MOS device modeling at 77 K. IEEE Trans. Electron Devices 1989, 36, 1464-1474. [CrossRef]

35. Dutta, G.; Turuvekere, S.; Karumuri, N.; DasGupta, N.; DasGupta, A. Positive shift in threshold voltage for reactive-ion-sputtered $\mathrm{Al}_{2} \mathrm{O}_{3} / \mathrm{AlInN} / \mathrm{GaN}$ MIS-HEMT. IEEE Electron Device Lett. 2014, 35, $1085-1087$. [CrossRef]

(C) 2019 by the authors. Licensee MDPI, Basel, Switzerland. This article is an open access article distributed under the terms and conditions of the Creative Commons Attribution (CC BY) license (http://creativecommons.org/licenses/by/4.0/). 